DOI: $10.17976 / j p p s / 2020.06 .14$

\title{
ПОКОЛЕНИЕ МИЛЛЕНИАЛОВ В РОССИЙСКОМ ОБЩЕСТВЕ: В ПОИСКАХ ДРУГОЙ МОЛОДЕЖИ
}

\author{
М.А. Ядова
}

ЯДОВА Майя Андреевна, кандидат социологических наук, зав. отделом социологии и социальной психологии, Институт научной информации по общественным наукам РАН, Москва, email: m.yadova@mail.ru

Ядова М.А. Поколение миллениалов в российском обществе: в поисках другой молодежи. - Полис. Политические исследования. 2020. № 6. С. 181-188. https://doi.org/10.17976/jpps/2020.06.14

Статья поступила в редакцию: 11.07.2020. Принята к публикации: 03.09.2020

\begin{abstract}
Аннотация. Опираясь на монографию В.В. Радаева “Миллениалы: как меняется российское общество” (М.: Изд. дом Высшей школы экономики, 2019), автор анализирует отличительные особенности поколения миллениалов, период взросления которого пришелся на 2000-е годы. На примере российских миллениалов показано, что получивший широкую известность концепт “советского простого человека" постепенно уходит в прошлое, и это делает важным создание альтернативных интерпретационных поколенческих схем. Подчеркивается, что на рубеже тысячелетий в России произошел социальный перелом, который обусловил формирование нового, “другого” поколения молодежи, сильно отличающегося от старших возрастных когорт. Рассматриваются сильные и слабые социальные ресурсы и индивидуальные особенности личности, помогающие адаптироваться к стремительно меняющимся социальным условиям. Сравнивая данные собственных социологических исследований с результатами, изложенными в рецензируемой книге, автор размышляет о взглядах и ценностях постсоветской молодежи, ее модернизационном потенциале и адаптивных способностях; оценивает соотношение современных и традиционных компонентов в системах ценностей представителей разных социальных групп молодежи. По мнению автора, при анализе социально-политических изменений, вызванных приходом новых поколений, необходимо учитывать, что постсоветская молодежь как социальная группа внутренне неоднородна и состоит из представителей разных - порой контрастных - подгрупп, различающихся по взглядам, объему социального капитала и особенностям социализационного опыта. Делается вывод, что в будущем при благоприятных внешних условиях отечественное поколение миллениалов может стать силой, способной к реальной социально-политической модернизации российского общества.
\end{abstract}

Ключевые слова: миллениалы, поколение, постсоветская молодежь, российское общество, социально-политическая модернизация.

Перезагрузка социально-политической системы и госуправления в России, провозглашенная В.В. Путиным в начале 2020 г., инициировала очередную волну дискуссий о необходимости трансформации - а значит, и модернизации, - российского общества. В процессе этих изменений особая роль отведена молодежи, взгляды и ценности которой, согласно Р. Инглхарту [Inglehart 1990], станут доминирующими в нашем социуме спустя 10-15 лет. Известно высказывание французской писательницы Жермены де Сталь о том, что в каждой 
стране молодое поколение - всегда иностранцы. Представители постсоветского поколения (иногда их называют миллениалами, поколением Y) - иностранцы вдвойне. Во-первых, это пока первое поколение, выросшее в "несоветской" России, что, несомненно, отличает его от более старших возрастных когорт. Однако именно его общество вправе рассматривать как хранителя демократических ценностей. Примечательно, что об этом поколении (“ровесниках новой, демократической России") как хранителе фундаментальных ценностей нашей страны в будущем в одном из посланий Федеральному Собранию говорил президент Д.А. Медведев (2008 г.)ํ. Во-вторых, определенная интрига имеется и в связи с тем, что сегодняшняя молодежь, не являясь единой, внутренне однородной общностью, представляет собой разные, порой контрастные подгруппы, отличающиеся друг от друга взглядами, объемом социального капитала и опытом гражданской и общественно-политической активности. Это дает возможность сказать, что юноши и девушки, взрослеющие при одних социальных обстоятельствах, оказываются “другими” по отношению к своим сверстникам, объединенным иными условиями жизни.

Для современных отечественных исследователей [Мельников 2016; Чирун 2011; Чекмарев 2009], занимающихся ювентологической проблематикой, характерен отход от объективированного к субъектному взгляду на молодежь, предполагающему стремление увидеть в новых поколениях самостоятельного актора модернизационных процессов, полноправного участника социальных и политических трансформаций в России. В настоящей работе мы также будем исходить из подобного понимания поколения миллениалов.

Термин "миллениалы" (от лат. millennium - тысячелетие) предложен в конце прошлого столетия американскими исследователями Н. Хоувом и У. Штраусом [Howe, Strauss 2000] для обозначения детей, которые должны были окончить среднюю школу на рубеже веков. В зависимости от региональной специфики взросления характеристики миллениалов разных стран варьируются. В Европе и США к этому поколению традиционно относят родившихся в 1981 - начале 2000-х годов, тогда как в России старшей когортой миллениалов принято считать ровесников горбачевской перестройки или тех, кто родился в период распада СССР.

Самым крупным исследованием российских миллениалов стал проект первого проректора НИУ ВШЭ профессора В.В. Радаева, результаты которого нашли отражение в рецензируемой книге "Миллениалы: как меняется российское общество” [Радаев 2019]. Автор пишет, что исследовательский интерес к молодежной и межпоколенческой проблематике с его стороны родился “из простого искреннего непонимания" [там же: 7] нового поколения студентов и того, что “их волнует, каковы их мотивы” [там же]. Это, по убеждению Радаева, вызвано тем, что более молодые поколения, не имея опыта советской жизни, повзрослев, начали воспроизводить новые поведенческие паттерны, делая происходящие сегодня социальные сдвиги необратимыми.

Разделив российские поколения в зависимости от исторических условий, в которых им пришлось вступать во взрослую жизнь, Радаев предложил собственную классификацию поколений: мобилизационное поколение (1941-1956), поколение оттепели (1956-1964), поколение застоя (1964-1984),

\footnotetext{
${ }^{1}$ Послание Федеральному Собранию Российской Федерации. - Президент России. Официальный сайт. 05.11.2008. URL: http://kremlin.ru/events/president/transcripts/1968 (accessed 25.08.2020).
} 
реформенное поколение (1985-1999), поколение миллениалов (1999-2016). Таким образом, отечественные миллениалы родились во время позднесоветских и постсоветских реформ (1982-2000), но их взросление происходило преимущественно с начала нового тысячелетия. В качестве источника информации автор книги использовал данные Российского мониторинга экономического положения и здоровья населения НИУ ВШЭ (RLMS-HSE) 25-й волны 2016 г. $(N=14946)$ и объединенный массив данных за 1994-2016 гг. $(N=258366)$.

Как и ожидалось, поколение миллениалов изрядно отличается от старших возрастных когорт. Миллениалы значительно позже своих сверстников из старших поколений вступают во взрослую жизнь, откладывая до более позднего возраста поступки, которые ассоциируются с обретением взрослости: достижение финансовой самостоятельности, отделение от родителей, выход на работу, вступление в брак, рождение детей [там же: 73]. Это связано прежде всего с нестабильными и сложными политическими и социальноэкономическими условиями, в которых пришлось взрослеть представителям этого поколения.

Миллениалов нередко называют цифровым, или сетевым, поколением, поскольку они намного активнее предшествующих поколений пользуются компьютером, интернетом, мобильными телефонами и социальными сетями [Радаев 2019: 80-85]. Помимо этого, миллениалы легко осваивают новые дистанционные практики (например, чаще совершают онлайн-покупки, используют банковские карты) [там же].

Более активны миллениалы и в проведении досуга. По сравнению со старшими возрастными группами они реже смотрят ТВ, зато намного чаще слушают музыку, аудиокниги, смотрят видео, совершают прогулки на природе, уделяют время развлечениям, а также активнее вовлечены в творческие и спортивные занятия. Чем миллениалы мало отличаются от предшествующих возрастных когорт, так это отношением к чтению: независимо от возраста, практически ежедневно читает книги каждый третий участник опроса [там же: 87-91].

Кроме того, миллениалы по сравнению с предыдущими поколениями потребляют сушественно меньше алкоголя, меньше курят и более расположены к ведению здорового образа жизни. По словам Радаева, снижение среди молодежи доли курящих наряду с уменьшением потребления алкоголя относительно недавний, причем международный, тренд [там же: 100].

Также представляются интересными межпоколенческие различия в зависимости от уровня религиозности участников опроса. Радаев, сравнивая в разных возрастных когортах доли тех, кто считает себя определенно верующим, обнаружил, что во всех поколениях число верующих постепенно снижается: с $56 \%$ в мобилизационном поколении до $32 \%$ у миллениалов [там же: 107]. Можно предположить, что подобная тенденция является протестной реакцией на усиление роли РПЦ в российском обществе.

Помимо этого, было обнаружено отсутствие значимых межпоколенческих различий при анализе уровня межличностного доверия. Немного более других склонны доверять окружающим представители самого старшего - мобилизационного - поколения $(22,2 \%)$. Во всех остальных поколениях этот показатель находится в интервале от $14 \%$ до 17\%, т.е. миллениалы никак не выделяются [там же: 109]. Следует отметить, что уровень межличностного доверия, как правило, прямо связан с уровнем материального благополучия населения и развитостью 
демократических институтов в обществе [Inglehart 1990: 34-38]. Судя по тому, что “недоверчивость" в нашем социуме можно считать воспроизводящимся феноменом, экономическое отставание России от мировых лидеров, вероятно, продолжится и когда ключевые посты во власти займут миллениалы.

Что касается оценок субъективного благополучия, то поколение миллениалов отличает большая удовлетворенность жизнью по сравнению с предшествующими поколениями (ср.: почти 60\% миллениалов и $30 \%$ в когорте пожилых) [Радаев 2019: 113]. Впрочем, это общепринятая закономерность: чем моложе человек, тем чаще он ощущает себя удовлетворенным жизнью.

В целом, как отмечает автор книги, выдвинутая ранее гипотеза о значимых отличиях миллениалов от предшествующих поколений нашла свое подтверждение. Вместе с тем полученные результаты не вписываются в единую схему закономерностей: межпоколенческие различия проявляют себя неодинаково. В одном случае анализируемые показатели возрастают от старших поколений к младшим (использование гаджетов и цифровых технологий) или, наоборот, постепенно снижаются (уровень религиозности). В другом случае все поколения демонстрируют сходство, несмотря на возрастные различия, за исключением выбивающихся из единого ряда миллениалов (здоровьесберегающее поведение и занятия спортом). В третьем случае наблюдается общее для всех поколений уменышение распространенности определенных практик, но миллениалы во многом обеспечивают перелом сложившихся ранее трендов (отношение к курению и потреблению алкоголя). В четвертом случае показатели миллениалов заметно выше, чем у старших поколений, но во многом это можно считать преходящим феноменом (субъективное благополучие).

Таким образом, подчеркивает В.В. Радаев, мы переживаем вторую волну фундаментальных социальных изменений, которые, в отличие от 1990-х годов, происходят в относительно стабильное время и связаны не с радикальными реформами, а с поколенческими сдвигами. Это, по его мнению, свидетельствует о том, что получившая широкую известность в отечественной социальной науке идея “советского простого человека” [Советский простой человек... 1993] постепенно уходит в прошлое (хотя и содержит значительные политические резонансы), что дает повод подумать об альтернативных интерпретационных и концептуальных схемах. Радаев предлагает ученым обратить более пристальное внимание даже не на одно, а на два самых активных сегодня поколения россиян - реформенное и миллениалов, взрослевших в перестроечный и постперестроечный периоды и ставших ключевыми акторами изменений в российском социуме.

Примечательно, что результаты проведенного автором настоящей статьи лонгитюдного исследования², посвященного современным и традицион-

\footnotetext{
2 В ходе исследования в период с 2008 по 2014 гг. с представителями постсоветской молодежи (когорта родившихся в начале 1990 -х годов) были проведены социологический опрос $(N=1600)$, серия индивидуальных и групповых глубоких интервью по специально разработанным оригинальным методикам. Изначально отбирались “контрастные” группы, различающиеся по объему социальных ресурсов, - условно сильноресурсная (старшеклассники) и слаборесурсная (учащиеся колледжей) подвыборки. На следующем этапе по результатам анкетирования в каждой подвыборке были выделены группы респондентов с модернистскими и традиционалистскими взглядами и поведенческими установками. Модернистскими считались характеристики так называемой современной личности, сформулированные американским социологом А. Инкелесом: открытость новому опыту, социальная ответственность и активность, законопослушность, толерантность, самостоятельность и пр. [Inkeles, Smith 1974]. Под традиционалистскими понимались черты, противоположные современным.
} 
ным ценностям постсоветской молодежи, во многом совпадают с данными В.В. Радаева. Мы исходили из предположения, что молодежь как социальная группа потенциально наиболее восприимчива к ценностям модерна и могла бы стать локомотивом социально-политических модернизационных процессов в нашей стране. И вот почему. Наибольшую способность к адаптации обычно демонстрируют обладатели сильного “личностного” капитала - комплекса индивидуально-психологических особенностей и социальных ресурсов человека, в числе которых специалисты обычно выделяют: удачный стартовый социостатусный капитал, хорошее образование и материальное положение, проживание в крупном городе, наличие обширных межличностных связей, адекватный уровень самооценки, интернальность, адаптивную гибкость, отсутствие страха перемен [Ядов 2001: 314-317]. Естественным ресурсом является и молодой возраст. В целом в условиях социальной турбулентности гипотетический успешный актор модернизации российского социума выглядит так: представитель молодого поколения с хорошим образованием, живущий в мегаполисе, обладающий достаточно сильным набором социальных ресурсов, открытый "современным" ценностям. По данным проведенного нами исследования, гипотеза о связи между модернизмом человека и объемом его социального капитала подтвердилась. Доля “модернистов” в сильноресурсной подвыборке молодежи выше, чем в слаборесурсной (23\% vs 5\%); “традиционалистов”, напротив, больше в слаборесурсной группе (15\% vs 7\%) (см., например, [Ядова 2016: 52]). Это говорит о неплохом модернизационном потенциале отечественного поколения миллениалов, особенно высокоресурсной его части.

Рассуждая об окончательном разрыве миллениалов с миром “советского”, В.В. Радаев намеренно выводит за скобки анализа политическую сферу, поскольку существует немало социологических и политологических данных, демонстрирующих неочевидность противопоставления миллениалов и homo soveticus. Особенно это было заметно в период Крымского кризиса - 2014, когда настроения молодежи по многим ключевым вопросам мало отличались от взглядов старших поколений. Например, результаты индивидуальных интервью с молодыми "модернистами" и “традиционалистами" в нашем исследовании показали, что тех и других объединяет тотальное недоверие отечественным политикам, однако это не касается действующего президента страны, авторитет которого после событий Русской весны только вырос. Давая оценки происходящему в Крыму, молодые информанты нередко переходили на почти “советскую” риторику, что свидетельствует о неизжитости великодержавного комплекса и у постсоветских поколений россиян [там же: 56]. Думается, тема соотношения советского и несоветского в системе ценностей миллениалов еще ждет всестороннего исследования, а пока отечественным обществоведам, вероятно, следует провести “инвентаризацию” имеющихся в их распоряжении научных подходов к изучению межпоколенческой проблематики.

В своих размышлениях В.В. Радаев старается уйти от слишком политизированного отношения к понятию "поколение". По его мнению, интерес к молодежи как к преимущественно акторам будущих политических преобразований нередко способствует разочарованию в молодых людях, не сумевших “оправдать надежд” старших. Ведь, по данным соцопросов, российское поколение миллениалов "не бросает вызов властной вертикали, не демонстрирует массового участия в протестных движениях” [Радаев 2019: 19], 
порой отличается “"ретроградным’ пониманием советской истории” [там же]. Мы не совсем согласны с таким подходом: вряд ли возможно в принципе исключить обсуждение политических вопросов из поколенческого анализа. К тому же существует достаточное количество исследований, результаты которых позволяют увидеть в миллениалах значительный политический ресурс модернизации российского общества [Чекмарев 2009]. Открытость новому, адаптивность и активность представителей этого поколения дают им хорошие возможности для реализации себя в качестве субъекта происходящих в нашей стране социально-политических изменений. Политологи (см., например, [Кольжанова 2006; Карпенко, Ламанов 2006; Чирун 2011]), как правило, отмечают следующие позитивные факторы модернизации российской политической системы в XXI в.: омоложение политической элиты страны, увеличение доли молодежи в наиболее активных и инновационных социальных группах (предпринимателей, управленцев и пр.), рост числа молодежных организаций и движений, формирование института молодых политических лидеров, выработка стратегии и механизмов привлечения юношей и девушек к участию в политическом процессе. Все это позволяет говорить об особом молодежном ресурсе в нашем обществе, роль которого состоит "не только в совершенствовании политической системы, но и обеспечении ее устойчивости в новых условиях российской цивилизационной специфики” [Чекмарев 2017: 90].

Помимо этого, можно предположить, что благодаря адаптивной гибкости и развитым цифровым навыкам миллениалы, вероятно, окажутся лучше, чем старшие поколения, приспособлены к жизни в новой постковидной действительности. Ответом на глобальные вызовы, связанные с пандемией COVID-19, стали новые практики солидарности и социального активизма (усиление онлайн-активизма, совместные действия государства и гражданского общество для борьбы с последствиями пандемии и пр.) в разных странах мира $^{3}$; появился запрос на изменение существующей политической, экономической и социокультурной реальности для минимизации дальнейших рисков в условиях посткоронавирусного кризиса. Именно молодежи предстоит стать первопроходцами в моделировании и освоении новых поведенческих паттернов и форм социального взаимодействия.

Подводя итоги, В.В. Радаев замечает, что при написании книги его не покидало свойственное социальным современным исследователям ощущение постоянного отставания: еще не до конца поняты миллениалы, а уже вступает во взрослую жизнь поколение Z. B то же время, по его мнению, вектор общественного развития, заданный миллениалами, достаточно устойчив, и кардинальные изменения вряд ли возможны. Впрочем, этот вопрос остается открытым, а ответ на него может дать только будущее. Как показывает практика, при подобных прогнозах невозможно игнорировать эмерджентные эффекты. В мире бушует пандемия COVID-19, неизвестно, что ждет человечество завтра. Очевидно лишь, что отвечать на эти вызовы предстоит и новым поколениям россиян - наиболее удобным и понятным для них способом, т.е.

\footnotetext{
${ }^{3}$ См., например, онлайн-вебинар, состоявшийся в апреле 2020 г. в рамках исследовательского комитета по изучению социальных классов и социальных движений Международной социологической ассоциации "Изменение солидарности и коллективных действий во время пандемии": Changing Solidarities and Collective Action in Times of Pandemic. URL: https://www.youtube.com/watch?v=1qBieYRF CIc\&feature=youtu.be (accessed 29.09.2020).
} 
В “своем стиле”. Одно это делает предпринятое В.В. Радаевым исследование не просто актуальным, а жизненно важным. Кроме того, нынешние реалии требуют усиленного осмысления представлений о новых поколениях, их возможностях и преимуществах в условиях новой повседневности. На наш взгляд, книгу В.В. Радаева стоит рассматривать не только как блестящую, высокопрофессиональную по содержанию и исполнению первую систематическую работу, посвященную отечественному поколению миллениалов, но и как программу для дальнейших научных изысканий на эту тему.

DOI: $10.17976 / \mathrm{jpps} / 2020.06 .14$

\title{
GENERATION OF MILLENNIALS IN RUSSIAN SOCIETY: IN SEARCH OF ANOTHER YOUTH
}

\author{
M.A. Yadova ${ }^{1}$ \\ ${ }^{1}$ Institute of Scientific Information for Social Sciences of the Russian Academy of Sciences. Moscow, Russia
}

YADOVA, Maiya Andreevna, Cand. Sci. (Soc.), Head of the Department of Sociology and Social Psychology, Institute of Scientific Information for Social Sciences of the Russian Academy of Sciences, email: m.yadova@mail.ru

Yadova M.A. Generation of Millennials in Russian Society: In Search of Another Youth. - Polis. Political Studies. 2020. No. 6. P. 181-188. (In Russ.) https://doi.org/10.17976/jpps/2020.06.14

Received: 11.07.2020. Accepted: 03.09.2020

\begin{abstract}
The author, relying on V.V. Radaev's monograph "Millennials: How Russian Society Changes", analyzes the distinctive features of the "millennial" generation, whose maturation period occurred in the 2000s. Using the example of Russian millennials, it is demonstrated that the widely known concept of the "Soviet common man" is gradually becoming outdated, which makes it crucial to develop alternative interpretational generation schemes. It is emphasized that at the turn of the millennium in Russia there was a significant social turning point, which led to the formation of a new, "different" generation of young people, very distinctive from their elder cohorts. Strong and weak social resources and individual personality traits that help adaptations to rapidly changing social conditions are considered. To compare the data of his own sociological studies with the results set forth in the book under review, the author reflects on the views and values of post-Soviet youth, its modernization potential, and the adaptive abilities. The correlation of modern and traditional components in the value systems of representatives from different young social groups is estimated. According to the author, when analyzing social changes caused by the arrival of new generations, it is necessary to take into account that post-Soviet youth as a social group is internally heterogeneous and consists of representatives of different - sometimes contrasting - subgroups, differing in their views, the volume of social capital, and the characteristics of socialization experience. It is concluded that in the future, under favorable external conditions, the domestic generation of millennials may become a force capable of real social and political modernization in Russian society.
\end{abstract}

Keywords: millennials, generation, post-Soviet youth, Russian society, social and political modernization.

\section{References}

Howe N., Strauss W. 2000. Millennials Rising: The Next Great Generation. New York: Vintage books. Inglehart R. 1990. Culture Shift in Advanced Industrial Society. Princeton, N.J.: Princeton University Press. Inkeles A., Smith D.H. 1974. Becoming Modern. Cambridge, M.A.: Harvard University Press.

Chekmarev E.V. 2009. Molodezh' - politicheskij resurs modernizacii postsovetskoj Rossii [Youth a Political Resource of Modernization of Post-Soviet Russia]. Saratov: PAGS. (In Russ.)

Chekmarev E.V. 2017. Youth Resource of Preserving the Stability of the Political System of Modern Russia. - Central Russian Journal of Social Sciences. Vol. 12. No. 2. P. 89-96. (In Russ.)

Chirun S.N. 2011. Youth Political Movements and the Organizations as Mechanisms and Realization Ways Independence Youth in Public Youth Policy. - Bulletin of Kemerovo State University. No. 1. P. 120-123. (In Russ.) Karpenko O.M., Lamanov I.A. 2006. Molodezh'v sovremennom politicheskom protsesse v Rossii [Youth Participation in the Contemporary Political Process]. Moscow: SGU. (In Russ.) 
Kolzhanova I.N. 2006. Obshhestvenno-politicheskie molodjozhnye dvizheniya v sovremennoj Rossii: massa, jelity, lidery [Social and Political Youth Movements in Modern Russia: Masses, Elites, Leaders]. Dissertation ... cand. sci. (pol. sci.). Rostov-on-Don. (In Russ.)

Mel'nikov A.V. 2016. The Effective Model of Political Socialization of Youth. - Vlast' (The Authority). Vol. 24. No. 3. P. 201-204. (In Russ.)

Radaev V. 2019. Millennials: How the Russian Society Changes. Moscow: HSE Publishing House. (In Russ.) https://www.doi.org/10.17323/978-5-7598-1985-1

Sovetskiy prostoy chelovek: Issledovanie sotsialnogo portreta на rubezhe 1990-kh [Soviet Ordinary Man: A Study of Social Portrait at the Edge of 1990s]. 1993. Ed. by Yu.A. Levada. Moscow: Mirovoy okean.

Yadov V.A. 2001. Social'nyj resurs individov i grupp kak ih kapital: vozmozhnost' primeneniya universal'noj metodologii issledovaniya real'nogo rassloeniya $v$ rossijskom obshchestve. [Social Resource of Individuals and Groups as Their Capital: An Applicability of the Universal Methodology of the Study of Real Stratification in Russian Society]. - Kto i kuda stremitsya vesti Rossiyu? [Where is Russia Going?] Ed. by T.I. Zaslavskaya. Moscow: The Moscow School of Social and Economic Sciences. P. 310-319. (In Russ.)

Yadova M.A. 2016. Crimean Crisis-2014 as Seen by the Post-Soviet Youth Generation. - Sociological Studies. No. 9. P. 50-58. (In Russ.)

\section{Литература на русском языке}

Карпенко О.М., Ламанов И.А. 2006. Молодежь в современном политическом процессе в России. М.: СГУ.

Кольжанова И.Н. 2006. Общественно-политические молодёжные движения в современной России: масса, элиты, лидеры. Дисс. ... канд. полит. наук. Ростов-на-Дону.

Мельников А.В. 2016. Эффективная модель политической социализации молодежи. - Власть. T. 24. № 3. C. 201-204.

Радаев В.В. 2019. Миллениалы: как меняется российское общество. М.: Изд. дом Высшей школы экономики. https://www.doi.org/10.17323/978-5-7598-1985-1

Советский простой человек: опыт социального портрета на рубеже 90-х. 1993. Отв. ред. Ю.А. Левада. М.: Мировой океан.

Чекмарев Э.В. 2009. Молодежь - политический ресурс модернизации постсоветской России. Саратов: ПАГС.

Чекмарев Э.В. 2017. Молодежный ресурс сохранения устойчивости политической системы современной России. - Среднерусский вестник общественных наук. Т. 12. № 2. С. 89-96.

Чирун С.Н. 2011. Молодежные политические движения и организации как механизмы реализации субъектности молодежи в публичной молодежной политике. - Вестник КемГУ. № 1. С. 120-123.

Ядов В.А. 2001. Социальный ресурс индивидов и групп как их капитал: возможность применения универсальной методологии исследования реального расслоения в российском обществе. - Кто и куда стремится вести Россию? Акторы макро-, мезо- и микроуровней современного трансформационного процесса. Под ред. Т.И. Заславской. М.: МВШСЭН. С. 310-319.

Ядова М.А. 2016. Крымский кризис-2014 глазами молодежи постсоветского поколения. Социологические исследования. № 9. С. 50-58. 